\title{
A FORMAÇÃO DO DIREITO AMBIENTAL A PARTIR DAS CONFERÊNCIAS DE ESTOCOLMO E RIO DE JANEIRO
}

The formation of environmental law from Stockholm conferences and Rio de Janeiro

César Augusto Modena ${ }^{1}$

Deise Salton Brancher ${ }^{2}$

\begin{tabular}{|c|c|}
\hline & ABSTRACT \\
\hline $\begin{array}{l}\text { Os danos ambientais não estão mais restritos ao } \\
\text { território dos Estados em que foram gerados. O Direito } \\
\text { Ambiental Internacional emergiu lentamente, } \\
\text { acompanhando a nova consciência ambiental. Não } \\
\text { existe um marco histórico do surgimento desse ramos } \\
\text { do direito, mas a Conferência de Estocolmo de } 1972 \text { e } \\
\text { a Conferência do Rio de Janeiro de } 1992 \text { são } \\
\text { consideradas fundamentais para a formação de um } \\
\text { regramento internacional sobre o meio ambiente. A } \\
\text { autonomia, a multidimensionalidade e a presença de } \\
\text { soft norms caracterizam o Direito Ambiental } \\
\text { Internacional. O regramento internacional ambiental } \\
\text { segue princípios gerais próprios. O descumprimento } \\
\text { das normas ambientais internacionais autoriza a } \\
\text { ingerência ecológica nos países poluidores pelas } \\
\text { demais nações. }\end{array}$ & $\begin{array}{l}\text { Environmental damage is no longer restricted to the } \\
\text { territory of States that were generated. The } \\
\text { International Environmental Law emerged slowly, } \\
\text { following the new environmental awareness. There is a } \\
\text { milestone in the emergence of this branch of law, but } \\
\text { the } 1972 \text { Stockholm Conference and the Conference of } \\
\text { Rio de Janeiro in } 1992 \text { are considered essential to the } \\
\text { formation of an international regramento on the } \\
\text { environment. Autonomy, the multidimensionality and } \\
\text { the presence of soft norms characterizing the } \\
\text { International Environmental Law. The international } \\
\text { environmental regramento following general principles } \\
\text { themselves. Failure to comply with international } \\
\text { environmental standards to allow polluters to } \\
\text { environmental interference by other nations. }\end{array}$ \\
\hline $\begin{array}{l}\text { Palavras-chave: Direito ambiental internacional. } \\
\text { Dano ambiental transfronteiriço. } \\
\text { Ingerência. }\end{array}$ & $\begin{array}{l}\text { Key-words: International environmental Law. } \\
\text { Transboundary environmental damage. Principles. } \\
\text { Interference. }\end{array}$ \\
\hline
\end{tabular}

\section{Introdução}

Por muitos séculos a humanidade compreendeu o meio ambiente como uma fonte inesgotável de recursos naturais, deixando bastante evidente sua concepção antropocêntrica ao se apropriar indiscriminadamente dessas riquezas para satisfazer as necessidades e os interesses apresentados pela sociedade.

O emprego irracional e desordenado dos recursos naturais provocou graves desequilíbrios ecológicos e comprovou a possibilidade de esgotamento. A ocorrência de

\footnotetext{
${ }^{1}$ Mestre e Doutor em Direito do Estado pela UFPR - Universidade Federal do Paraná. Professor da Universidade de Caxias do Sul e do Centro de Ensino Superior de Farroupilha. Advogado. cesar.modena@senairs.org.br ${ }^{2}$ Mestranda em Direito Ambiental pela Universidade de Caxias do Sul. Especialista em Direito Previdenciário pela ESMAFE - UCS. Bolsista da CAPES. Advogada. dbrancher@bol.com.br
} 
144

tragédias ambientais, inicialmente limitadas no espaço geográfico, exigiu dos governos locais o estabelecimento de normas voltadas à preservação ambiental.

Contudo, principalmente a partir do século passado, os desastres ambientais atingiram proporções globais, ultrapassando fronteiras, ameaçando a continuidade da vida no planeta e gerando conflitos na comunidade internacional, especialmente divergências de ordem econômica, a exemplo do incidente conhecido como Trail Smelter Case (CESÁRIO: 2011), em que as emissões tóxicas geradas por uma fábrica instalada no Canadá afetavam os habitantes da cidade vizinha norte-americana.

O aumento e a magnitude dos desastres ambientais despertaram a opinião da comunidade internacional, que passou a reconhecer a necessidade de uma regulamentação protetiva, preventiva e punitiva do meio ambiente no âmbito internacional que contasse com a participação de todas as nações, oportunizando a formação de um direito ambiental internacional.

Assim, o presente artigo tem por objetivo analisar a emergência do direito ambiental no âmbito internacional, seus aspectos históricos e elementos característicos, assim como os princípios que norteiam esse novo ramo do Direito e o confronto existente entre a ingerência ecológica e o exercício da soberania.

\section{A emergência do direito ambiental no âmbito internacional}

O Direito Ambiental Internacional, já existia sob a geração de normas válidas entre determinados países. Considerando os interesses de países, por exemplo, que não fazem fronteira com o mar, surgiu limitações, em determinados períodos históricos, da pesca de determinadas espécies no Atlântico Norte. Em outros casos, rios que possuem nascentes em um país e banham terras de outros, necessitam de garantia de preservação para abastecimento de outras comunidades. Por isso, o caráter transfronteiriço da preservação de recursos naturais não é novidade. Contudo, a tentativa de globalizar, na tentativa de manter uma hegemonia econômica e ambiental é fato mais recente, como veremos.

A apropriação dos recursos naturais pode gerar danos ambientais de grande amplitude, que desrespeitam fronteiras geográficas, políticas e jurídicas, como ocorre com as chuvas 
ácidas, o desaparecimento de espécies animais e vegetais, a diminuição da camada de ozônio, a escassez de água potável.

As grandes catástrofes ambientais presenciadas nos últimos tempos comprovam que a intervenção desmedida do homem sobre a natureza tem como conseqüência a ocorrência de danos ambientais que ultrapassam as demarcações territoriais. Carrera e Séguin (2001; p. 49) assim comentam sobre os efeitos transfronteiriços da degradação ambiental:

Não há fronteiras para os efeitos de uma atividade impactante. O Planeta é um sistema fechado, assim, o que se faz num país repercute no outro. Polui-se aqui, chove ácido ali. Todos estamos direta e indiretamente ligados, como em uma teia de aranha, onde o toque de um ponto é sentido em qualquer parte da teia.

Desse modo, os efeitos globais na degradação ambiental exigiram uma regulamentação jurídica de abrangência igualmente global, exigindo a formação de um Direito Ambiental Internacional, assim compreendido por Guerra (2006; p. 441):

\begin{abstract}
Assim, o Direito Ambiental Internacional pode ser traduzido em um conjunto de normas que criam direitos e deveres para os vários atores internacionais (não apenas para os Estados), numa perspectiva ambiental, atribuindo igualmente responsabilidades e papéis que devem ser observados por todos no plano internacional, visando à melhoria da qualidade de vida para as presentes e futuras gerações.
\end{abstract}

Contudo, inserção das questões ambientais nas pautas da comunidade internacional, e mais ainda a formalização de normas jurídicas dotadas de eficácia, ocorreu de forma lenta, determinada pela gradual conscientização de indivíduos e governos acerca da efetiva possibilidade de concretização dos riscos decorrentes das atividades humanas sobre o meio ambiente, conforme assinala Oliveira (2007; p. 104):

Após uma tomada de consciência acerca dos riscos que o crescimento demográfico sem controle, o aumento do consumo de energia e os danos ecológicos poderiam causar para o equilíbrio natural da Terra, a comunidade internacional percebeu que o meio ambiente requer uma regulamentação na qual esteja presente a participação e cooperação de todos os Estados.

A afirmação da ciência da ecologia igualmente desencadeou o acirramento dos debates, uma vez que, favorecida pelo desenvolvimento científico e tecnológico, ofereceu 
conhecimentos técnicos para a compreensão da relação existente entre os seres e o meio em que vivem, assim como para fundamentar as várias suspeitas de eminentes desastres ambientais de grandes proporções.

E considerando que a mudança da consciência ambiental internacional ocorreu de forma gradual, assim como não contou com a imediata participação de todas as nações, inexiste no Direito Internacional um marco oficial da regulamentação de direitos e deveres do meio ambiente.

Não obstante, a Conferência de Estocolmo, realizada em 1972, e a Conferência do Rio de Janeiro, ocorrida em 1992, que serão abordadas pormenorizadamente no presente estudo, são consideradas eventos determinantes para a celebração de importantes atos internacionais multilaterais e para o desenvolvimento do Direito Ambiental na seara internacional.

\section{A Conferência de Estocolmo de 1972}

Atendendo a recomendação do Conselho Econômico e Social e as reivindicações dos movimentos ambientalistas liderados pelos países desenvolvidos, e considerando os desastres ambientais de grandes proporções que vinham ocorrendo, em 1968, a Assembléia Geral da Organização das Nações Unidas aprovou a convocação de uma conferência internacional para tratar do meio ambiente humano.

Em 1972, foi realizada a Conferência de Estocolmo sobre o Meio Ambiente, cujo evento culminou na aprovação de três importantes documentos: a Declaração de Estocolmo, o Plano de Ação para o Meio Ambiente e o Programa das Nações Unidas para o Meio Ambiente.

A Declaração das Nações Unidas sobre o Meio Ambiente, segundo Viana (1998; p. 920), "foi o primeiro grande passo dado, em âmbito internacional, para a tutela jurídica do meio ambiente, tendo a importância equivalente à Declaração dos Direitos do Homem." Entre os vinte e seis princípios da Declaração é possível reconhecer a preocupação com temas como poluição, políticas ambientais, educação ambiental, cooperação entre os Estados, responsabilidade, crescimento demográfico, bem como o direito à vida digna. 
O Plano de Ação para o Meio Ambiente continha recomendações voltadas para o desenvolvimento de políticas ambientais, divididas em três principais ramos de atuação, conforme assinala Soares (2003; p. 54):

2. um Plano de Ação para o Meio Ambiente, conjunto de 109 recomendações, centrada em três grandes tipos de políticas: (a) as relativas às avaliação do meio ambiente mundial, o denominado "Plano Vigia" (Earthwatch); (b) as de gestão do meio ambiente; e (c) as relacionadas às medidas de apoio (como a informação, educação e formação de especialistas);

O Programa das Nações Unidas para o Meio Ambiente - PNUMA foi instituído para desenvolver programas de ação a nível internacional e para proteção do meio ambiente e tem como principais objetivos "manter o estado do meio ambiente global sob contínuo monitoramento; alertar povos e nações sobre problemas e ameaças ao meio ambiente e recomendar medidas para aumentar a qualidade de vida da população sem comprometer os recursos e serviços ambientais das futuras gerações."

A Conferência de Estocolmo e os documentos aprovados na ocasião representam um grande marco na evolução do Direito Ambiental Internacional, impondo aos governos o enfrentamento de uma situação fática e jurídica extremamente delicada e em vias de exaurimento. Contudo, também revelaram um conflito diplomático que emergiu entre os países desenvolvidos e os países em desenvolvimento no final dos anos de 1960, cuja dissidência é assim explicada por Varella (2003; p. 30):

\begin{abstract}
A pressão em favor dos limites ambientais pedidos aos países do Sul era vista como um instrumento utilizado pelo Norte para bloquear o desenvolvimento econômico dos países emergentes; atitude esta refletida nos discursos dos diplomatas do Sul, que se opunham à questão ambiental e defendiam o mesmo direito de destruir a natureza que tinham usufruído os países do Norte durante as épocas de maior desenvolvimento econômico.
\end{abstract}

Ainda assim, a Conferência de Estocolmo oportunizou a identificação e a compreensão dos problemas ambientais, especialmente porque estes estão intimamente ligados a questões econômicas e políticas (OLIVEIRA: 2007; p. 141) assim como iniciou uma mudança na consciência da comunidade mundial e possibilitou a celebração de inúmeros 
acordos e tratados internacionais de preservação ambiental, impulsionando o desenvolvimento do Direito Ambiental Internacional.

\section{Conferência do Rio de Janeiro de 1992}

Nos vinte anos seguintes à Conferência de Estocolmo, concomitantemente à celebração de inúmeros acordos internacionais multilaterais de preservação ambiental, e a intensa atuação de movimentos ambientalistas, a humanidade verificou o crescimento econômico dos países desenvolvidos, a emergência de alguns países em desenvolvimento, o avanço tecnológico e científico, mas igualmente presenciou miséria, desigualdades sociais, aumento da degradação dos recursos naturais e catástrofes ambientais sem precedentes.

Em 1987, esse cenário mundial foi denunciado pelo Relatório Brundtland, que identificou a poluição ambiental, a diminuição dos recursos naturais e problemas de natureza social como as principais questões ambientais a serem enfrentadas por todas as nações, e apontou o desenvolvimento sustentável como "a forma de desenvolvimento que satisfaz às necessidades das gerações presentes sem comprometer a capacidade das gerações futuras de alcançar a satisfação de seus próprios interesses" (GUERRA: 2006, p. 444-445).

Tendo como base o Relatório de Brundtland, no ano de 1992, ocorreu a Conferência das Nações Unidas sobre o Meio Ambiente e Desenvolvimento - ECO/92, sediada no Rio de Janeiro. A escolha do Brasil como sede da segunda grande conferência sobre o meio ambiente foi especialmente influenciada pela opção ambientalista da Constituição Federal de 1988, que elevou os direitos ambientais à condição de direitos fundamentais, conforme assinala Soares (2003; p. 88):

Com efeito, foram tais mandamentos constitucionais, que determinaram à política exterior brasileira reconduzir-se e fixar-se num rumo definido na sua opção ambientalista e, portanto, com base numa inequívoca política determinada pelo legislador constituinte, a opção diplomática pelo meio ambiente transformar-se-ia de uma política circunstancial ou episódica em uma preocupação constante e dominante nas relações internacionais do Brasil, uma vez que o meio ambiente se havia transferido para a esfera constitucional, inserto, pois, dentro das normas fundamentais do Estado brasileiro. 
O título da Conferência do Rio de Janeiro indica a nova diretriz que a comunidade internacional passaria adotar em termos de meio ambiente, estando agora voltada para o desenvolvimento sustentável, ou seja, preservar o meio ambiente para as gerações presentes e futuras sem olvidar da necessidade de desenvolvimento sócio-econômico para que os indivíduos tenham suas necessidades básicas satisfeitas.

$\mathrm{Na}$ Conferência do Rio de Janeiro foram produzidos cinco importantes instrumentos diplomáticos: a Convenção da Diversidade Biológica, a Convenção sobre Mudanças Climáticas, a Agenda 21, a Declaração do Rio sobre Meio Ambiente e Desenvolvimento e a Declaração de Princípios sobre as Florestas.

Segundo Wold (2003; p. 8), a Convenção da Diversidade Biológica e a Convenção sobre Mudanças Climáticas representam os resultados mais relevantes da ECO/92 para o processo de formulação do Direito Internacional do Meio Ambiente, pois apresentaram uma abordagem holística de problemas ambientais globais.

A Agenda 21 propõe um programa de ação voltado para o desenvolvimento mundial, oferecendo linhas gerais para as convenções-quadro. É considerada por Varella (2003; p. 65) o texto mais concreto, na medida em que prevê com precisão as deficiências das instituições internacionais e nacionais e apresenta um tom de denunciação, prevendo prazos, recursos e estabelecendo os responsáveis por cada ação.

A Declaração do Rio sobre Meio Ambiente e Desenvolvimento e a Declaração de Princípios sobre as Florestas apresentam um conjunto de princípios que reconhecem o meio ambiente como um direito intergeracional e propõem políticas ambientais de âmbito global para proteção dos recursos naturais, aqui abrangidas a cultura e a identidade dos povos.

Assim, a Conferência do Rio de Janeiro, marcada pelo discurso pautado no desenvolvimento sustentável e na intergeracionalidade do direito ao meio ambiente equilibrado, aflorou a consciência de que o meio ambiente é um valor global e que extrapola as fronteiras políticas e jurídicas dos Estados, inaugurando um novo capítulo no Direito Internacional, o Direito Internacional do Meio Ambiente.

\section{Características do Direito Ambiental Internacional}


O Direito Ambiental Internacional emergiu lentamente a partir conscientização da comunidade global acerca da importância da preservação do meio ambiente, cujo processo iniciou entre os países desenvolvidos, tendo se consolidado como ramo do direito a partir da Conferência de Estocolmo e da Conferência do Rio de Janeiro.

Portanto, a formação do Direito Ambiental Internacional ocorreu de forma desordenada e heterogênea, sem que haja um marco determinado e especialmente marcada por conflitos de interesses econômicos entre países desenvolvidos e países em desenvolvimento, conforme assinala Varella (2003; p. 21-22):

\footnotetext{
O direito ambiental internacional nasceu de forma particularmente complexa, oriundo de um processo desordenado que tem origem em diferentes fontes, com normas de valores distintos, e superposição de regras tratando do mesmo tema, para as quais cada Estado vota a favor ou contra, inspirando-se em lógicas diferentes. No entanto, este direito constrói-se sem qualquer coordenação, no âmbito internacional.
}

No entanto, ainda que sua gênese seja marcada pela complexidade e pela desordem, o Direito Ambiental Internacional é identificado por sua autonomia, pois apresenta evolução diferenciada no tempo e no espaço, finalidade específica de tutelar o meio ambiente em sua dimensão global, objeto próprio, meios regulatórios e produção normativa peculiares (OLIVEIRA: 2007; p. 113-114).

O Direito Ambiental Internacional também é multidimensional, tendo vista sua necessária interação com outros ramos do Direito, a exemplo do Direito Constitucional, uma vez que o direito ambiental é inegavelmente um direito fundamental, assim como com outras áreas do conhecimento, conforme nos assinala Oliveira (2007; p. 123)

\begin{abstract}
A abordagem das questões relativas à proteção ao meio ambiente exige uma análise em conjunto com as demais áreas do conhecimento, pois lida com valores e interesses que são atingidos pelas medidas tomadas para o alcance de seus objetivos. Uma das faces desse direito está intimamente ligada à própria evolução da ciência e tecnologia, tendo em vista que são os avanços nessas áreas que ora servem como instrumentos de proteção, ora atuam como causadores de dano ambiental.
\end{abstract}

Outra importante característica distintiva do Direito Ambiental Internacional é a presença de normas desprovidas de obrigatoriedade, na medida em que, embora se manifeste 
como um direito positivado em tratados e acordos entre as nações, normas cogentes convivem com normas desprovidas de coercitividade.

Varella (2003; p. 24) leciona que a acumulação de normas cogentes e soft norms é uma das principais características do Direito Ambiental Internacional, e que o nível de obrigatoriedade e eficácia dessas normas é determinado pelo comportamento dos Estados contratantes, o que acaba por gerar incerteza e insegurança jurídica.

A flexibilidade de grande parte das normas jurídicas internacionais referentes ao meio ambiente reflete não apenas na sua normatividade, mas igualmente na sua aplicabilidade, conforme explica Oliveira (2007; p. 130):

\begin{abstract}
Ou seja, a sua flexibilidade e a sua evolutividade manifestam-se por meio dos instrumentos empregados, bem como pelo conteúdo das disposições adotadas. Quanto aos instrumentos, seu caráter soft é revelado pela ausência de força jurídica vinculante expressa em diversos tipos de mecanismos, dentre eles: resoluções, declarações, programas, códigos de conduta, atos finais de conferências internacionais. Quanto ao seu conteúdo, o mesmo pode ser manifestado em normas em "gestação", ou seja, ainda não totalmente consolidadas ou acabadas.
\end{abstract}

Nesse sentido, o Direito Ambiental Internacional, que emergiu de modo desordenado e complexo, acabou por se consolidar como um ramo autônomo e multidimensional, que encontra agora o desafio de atribuir as suas normas a necessária obrigatoriedade, a fim de que alcance a almejada eficácia.

\title{
5 Princípios norteadores do Direito Ambiental Internacional
}

Assim como todos os ramos de um sistema jurídico, o Direito Ambiental Internacional é norteado por princípios gerais que funcionam como valores fundamentais para a estruturação das normas jurídicas, bem como para a aplicação destas ao caso concreto. Sobre a importância dos princípios para a afirmação do Direito Ambiental Internacional, Wold (2003; p. 6-7) afirma que:

No plano internacional, tais princípios não são, tecnicamente, considerados obrigatórios, não obstante, por influenciarem a estruturação do direito ambiental interno e por serem efetivamente empregados pelos formuladores da política 
ambiental internacional, eles possuem uma importância ímpar para a proteção do meio ambiente em âmbito local e internacional.

Considerando que o Direito Ambiental Internacional é concomitantemente autônomo e multidimensional, alguns de seus princípios possuem íntima relação com outros ramos do conhecimento, como a economia, por exemplo, enquanto outros são próprios das relações a nível internacional, conforme se observará a partir da análise de seus princípios mais elementares.

O princípio da soberania permanente sobre os recursos naturais surgiu ao final da década de 1950, quando os países em desenvolvimento, muitos deles recentemente descolonizados, buscavam instrumentos para eliminar práticas muito comuns de apropriação de seus recursos naturais pelos países desenvolvidos e, posteriormente, pelas empresas estrangeiras.

Segundo esse princípio, que tem por base o direito à autodeterminação e à independência econômica e está previsto no artigo $2^{\circ}$ da Declaração do Rio, o Estado é soberano para explorar os seus recursos naturais em prol do desenvolvimento de seu povo. Contudo, a essencialidade dos recursos naturais e a dimensões globais dos danos ambientais exigem a relativização dessa soberania e sua compatibilização os demais princípios, como o da responsabilidade (GUERRA, 2006; p. 448) e o do dever de não causar dano ambiental.

O princípio do direito ao desenvolvimento também surgiu no final da década de 1950, associado ao processo de descolonização, porém emergiu no âmbito do direito econômico internacional, quando os países em desenvolvimento repetiam o modelo de crescimento econômico dos países desenvolvidos.

Em decorrência do avanço das doutrinas noeliberais, o direito ao desenvolvimento recuou no direito econômico internacional, mas avançou no direito ambiental internacional, principalmente a partir dos anos 90, demonstrando imprescindibilidade do desenvolvimento para que as pessoas vivam com qualidade, possibilitando a construção jurídica do conceito de desenvolvimento sustentável (VARELLA: 2003; p. 21).

$\mathrm{Na}$ lição de Wold (2003, p. 11), o direito ao desenvolvimento apresenta dois componentes elementares. O primeiro consiste na reafirmação da soberania permanente sobre os recursos naturais e o segundo afirma que os indivíduos têm o direito fundamental a 
contribuir e participar do desenvolvimento cultural, político, econômico e social de sua nação, cujo direito deve ser protegido pelo Estado. Significa dizer que Estados e cidadãos têm o direito de serem economicamente independentes, podendo se utilizar dos recursos naturais de forma sustentável para alcançar essa finalidade.

O princípio da responsabilidade comum, mas diferenciada, surgiu de forma mais expressiva com os debates travados na Conferência do Rio de Janeiro, também por pressão dos países em desenvolvimento, podendo ser reconhecido nos instrumentos multilaterais subscritos naquele evento, conforme se verifica no sétimo artigo da Declaração do Rio de Janeiro:

\footnotetext{
Os Estados deverão cooperar em espírito de solidariedade mundial para conservar, proteger e restabelecer a saúde e a integridade do ecossistema da Terra. Na medida em que tenham contribuído em graus variados para a degradação do meio ambiente mundial, os Estados têm responsabilidades comuns, mas diferenciadas.
}

O referido artigo propõe que todos os Estados sejam solidários e unam esforços em prol da permanente preservação dos recursos naturais, mas recomenda que a responsabilidade em face da degradação ambiental seja fixada segundo o grau de degradação ambiental mundial provocado por cada nação.

Segundo Wold (2003; p. 15-16), esse princípio, que tem sido parâmetro para a solução de conflitos transfronteiriços, evidencia que os países desenvolvidos degradam mais que os países em desenvolvimento, e que aqueles possuem mais recursos financeiros e tecnológicos para implementar normas protetivas, preventivas e corretivas. Assim, resta justificado o pleito dos países em desenvolvimento no sentido de que os Estados sejam responsabilizados pelos danos que efetivamente causarem.

O princípio da precaução, que segundo Derani é a essência do Direito Ambiental (2008; p. 149), orienta a comunidade internacional pela abstenção da realização das atividades sobre as quais recaiam incertezas científicas acerca da ocorrência de riscos ambientais, com vistas à sustentabilidade e à proteção intergeracional.

A aplicação do princípio da precaução antecede não apenas ao dano, mas ao próprio risco, e tem sido de grande importância para a tomada de decisões no âmbito do Direito Ambiental Internacional, conforme salienta Derani (2005; p. 95): 
154

Por suposto, o princípio da precaução reflete a tendência do direito internacional ambiental de que a melhor proteção ao meio ambiente está na prevenção do que na remediação de danos muitas vezes irreparáveis ou na recuperação do ambiente por meio de medidas protetivas.

O princípio da precaução vem recebendo cada vez mais atenção do direito internacional, na medida em que reflete a necessidade de tomada de decisões que possam antever prováveis danos ambientais causados por substâncias ou produtos dos quais não se tem ainda certeza científica quanto ao seu impacto no meio ambiente.

Contudo, no que tange à implementação desse princípio, Wold (2003; p. 18) denuncia que existem divergências acerca do grau de incerteza da ocorrência de danos ambientais, e exemplifica que os tribunais domésticos aplicam o princípio da precaução diante da mínima evidência objetiva de risco, enquanto a OMC exige um conjunto maior de evidências e tolera certo grau de risco.

O princípio do poluidor-pagador, contido no artigo 16 da Declaração do Rio, é um instrumento de política ambiental que obriga os empreendedores a arcarem com os custos ambientais decorrentes da atividade econômica que exploram. Essa internalização de custos ambientais a ser imposta pelo Estado obriga os atores econômicos a adotarem medidas de prevenção, controle e reparação dos impactos negativos decorrentes produção de seus bens e serviços.

Assim, Derani (2005; p. 109) lembra que "a idéia central é de que, além da imposição de um regime de responsabilidade jurídica pelo dano ambiental, o princípio do poluidorpagador induza ou fortaleça mecanismos de mercado que sejam instrumentos aptos a inibir a ação prejudicial ao meio ambiente".

O princípio do dever de não causar dano ambiental representa um compromisso que indivíduos e Estados assumem perante a comunidade internacional que integram de atuar de forma diligente, tendo em vista que o meio ambiente caracteriza um bem de preocupação comum a toda a humanidade e que conta com vários titulares, mas está sujeito a degradação em proporções globais.

Em decorrência desse princípio surge para os Estados um dever específico de regulamentar e fiscalizar as atividades que exigem apropriação de recursos naturais realizadas em seu território, especialmente mediante a internalização dos acordos multilaterais celebrados e a criação de um conjunto de normas internas que efetivamente protejam o bem ambiental. 
O princípio da responsabilidade estatal complementa o princípio anterior e demonstra a preocupação da comunidade internacional com os danos ambientais transfronteiriços, atuando como limite para a soberania. Se por um lado os Estados gozam do direito de se apropriar dos recursos naturais existentes em seu território, por outro, têm o dever de regulamentar e fiscalizar as atividades desenvolvidas sob sua jurisdição, em atenção às normas internacionais a que se obrigaram, a sob pena de terem que arcar com os danos que atingirem outros territórios.

O princípio do desenvolvimento sustentável chegou a ser debatido na Conferência de Estocolmo, mas foi na Conferência do Rio de Janeiro que a comunidade internacional procurou melhor compreender sua abrangência. Vários artigos da Declaração do Rio de Janeiro fazem referência à necessidade de equilibrar desenvolvimento econômico e meio ambiente, a fim de não comprometer o atendimento das necessidades da geração presente, tampouco as das futuras.

A pretensão do princípio do desenvolvimento sustentável não é impedir o desenvolvimento econômico, mas que a humanidade planeje racionalmente esse necessário crescimento, com atenção à esgotabilidade e à intergeracionalidade dos recursos naturais. Nesse sentido Guerra (2006; p. 446) assinala:

\footnotetext{
Busca-se com isso a coexistência harmônica e proporcional entre econômica e meio ambiente, permitindo-se o desenvolvimento de forma sustentável, planejada, para que os recursos hoje existentes não se esgotem ou se tornem inócuos, isto é, o desenvolvimento sustentável é o princípio que busca encontrar o equilíbrio entre a atividade econômica e o uso adequado, racional e responsável dos recursos naturais para as gerações atuais e futuras.
}

Os recursos naturais representam a matéria-prima do desenvolvimento econômico, e o desenvolvimento econômico se revela imprescindível para que os indivíduos vivam com qualidade e dignidade, mas somente um ambiente ecologicamente saudável, equilibrado e sustentável possibilita uma vida digna.

\section{Ingerência ecológica}


A partir dos princípios anteriormente analisados, a maioria deles reconhecidos na Declaração do Rio de Janeiro de 1992, é possível concluir que os Estados, no exercício de sua soberania, têm o direito de explorar os recursos naturais existentes em seu território com a finalidade de promover o seu desenvolvimento.

Não obstante, oferecendo equilíbrio ao exercício da soberania estatal, igualmente é imputado aos Estados um dever de cooperação e de solidariedade na proteção do meio ambiente. Para honrar esse compromisso, os Estados devem adotar a necessária cautela frente aos riscos decorrentes das atividades desenvolvidas sob sua jurisdição, além de lhes ser atribuída a responsabilidade diante da ocorrência de danos ambientais que ultrapassem suas fronteiras e venham a atingir outros Estados.

A própria Declaração do Rio de Janeiro, em seu princípio 18, determina que os Estados comuniquem imediatamente os demais a ocorrência de eventos naturais ou emergências que possam provocar danos ambientais transfronteiriços.

Desse modo, uma vez excedido o exercício da soberania sobre os recursos naturais e desatendidas as obrigações assumidas frente aos demais entes internacionais, é plenamente admissível que os Estados sofram intervenção. Nessa hipótese, a ingerência se revela lícita, funcionando como controle legítimo por parte de um parceiro que se acha prejudicado pela execução ou inexecução de um compromisso entre Estados (BACHELET: 1997; p. 246).

Varella refere que a ingerência ecológica ainda não ocorreu e que inexiste previsão expressa para tanto nas normas internacionais. No entanto, o autor lembra que o meio ambiente já foi citado como bem passível de fundamentar a ingerência, mesmo que ao lado de outros bens jurídicos quem sabe até menos importantes. Por isso, Varella (2003; p. 119) compreende que o maior obstáculo foi vencido, qual seja, o reconhecimento da possibilidade de intervenção para defesa do meio ambiente e da necessidade de se adotar um conceito relativo de soberania para a soluções destas questões.

Nesse aspecto, o Conselho de Segurança da ONU, órgão competente para autorizar as intervenções, já se manifestou no seguinte sentido de que "a ausência de guerra e conflitos militares entre os Estados não garante por si só a paz e a segurança internacional. As fontes não-militares de instabilidade nos campos econômico, social, humanitário e ecológico se tornam ofensas à paz e à segurança” (VARELLA: 2003; p. 119). 
A possibilidade de intervenção ecológica decorre da consciência de que os recursos naturais são essenciais para a manutenção da vida e condicionam a existência da humanidade, mas estão dispostos na natureza de forma significativamente desigual e caminham para o esgotamento.

Nesse sentido, o comprometimento de todas as nações em proteger o meio ambiente e o direito de exigir o cumprimento das obrigações assumidas na seara internacional autorizam a ingerência ecológica, aqui compreendida não como um procedimento de eliminação da soberania estatal, mas de sua relativização em nome de algo maior e mais importante que é a manutenção da vida.

\section{Conclusão}

As atividades humanas alcançaram tal nível de interação com a natureza que os danos ambientais decorrentes de atividades realizadas em determinado país não estão mais restritos ao seu território, podendo gerar prejuízos de toda ordem em outros Estados, ou mesmo em todo o planeta, como ocorre com a poluição atmosférica transfronteiriça e com a diminuição da camada de ozônio.

Assim, a degradação ambiental provocada pelo homem transpôs as fronteiras geográficas e exigiu a formação de um regramento internacional. No entanto, o desenvolvimento do Direito Ambiental Internacional ocorreu lentamente, acompanhando a mudança de consciência da comunidade global, que gradualmente reconheceu a essencialidade do meio ambiente para o desenvolvimento da sociedade e, principalmente, para a manutenção da vida no planeta.

Embora não exista um marco histórico pontual do surgimento do Direito Ambiental Internacional, a Conferência de Estocolmo e a Conferência do Rio de Janeiro, realizadas em 1972 e 1992, respectivamente, oportunizaram o debate entre as nações acerca dos problemas ambientais e a formação de um sistema jurídico global para a solução de problemas que transcendem o território de cada Estado.

A Conferência de Estocolmo promoveu a identificação e a compreensão de muitos problemas ambientais, ocorridos tanto a nível local como global, e culminou na aprovação da 
Declaração de Estocolmo, o Plano de Ação para o Meio Ambiente e o Programa das Nações Unidas para o Meio Ambiente.

Vinte anos depois, a Conferência do Rio de Janeiro acirrou o debate acerca do desenvolvimento sustentável e da intergeracionalidade dos recursos ambientais, assim como oportunizou a celebração da Convenção da Diversidade Biológica, da Convenção sobre Mudanças Climáticas, da Agenda 21, da Declaração do Rio sobre Meio Ambiente e Desenvolvimento e da Declaração de Princípios sobre as Florestas.

Esses importantes documentos, e outros tantos instrumentos celebrados na seara internacional, assinalam que, embora a emergência do Direito Ambiental Internacional tenha ocorrido de forma desordenada e heterogênea, esse ramo do direito se consolidou como autônomo e multidimensional e segue importantes princípios para a formulação das normas e para a tomada de decisão - soberania permanente sobre os recursos naturais; direito ao desenvolvimento; responsabilidade comum, mas diferenciada; precaução; poluidor-pagador; dever de não causar dano ambiental; responsabilidade estatal; e desenvolvimento sustentável.

O Direito Ambiental Internacional enfrentou muitas dificuldades para se consolidar, a exemplo da resistência dos países em desenvolvimento e da falta de cooperação de alguns países desenvolvidos. Ainda, a convivência de normas cogentes com normas de pouca ou nenhuma obrigatoriedade também representa um fator a dificultar a eficácia do Direito Ambiental no âmbito internacional.

Mesmo com a presença de soft norms, é certo que todos os Estados têm o dever de colaborar com a política internacional de preservação ambiental, respeitando os acordos que firmaram, adotando medidas de proteção, prevenção e reparação, e evitando a ocorrência de danos ambientais locais, assim como de catástrofes que transcendam os limites geográficos e afetem outras nações.

Ao desconsiderarem as normas internacionais ambientais, os Estados violam seu dever de colaboração e solidariedade, especialmente quando da sua transgressão se verificar danos ambientais transfronteiriços, autorizando, assim, a intervenção em seus territórios pelos demais membros da comunidade internacional.

A ingerência ecológica imponha limites ao exercício absoluto da soberania estatal, rompendo com uma cultura milenar de livre apropriação dos recursos naturais pelos Estados, 
ela tem o papel político de lembrar às nações que, sem olvidar do direito das nações ao desenvolvimento, o meio ambiente equilibrado e a vida digna são direitos de toda a humanidade.

Porém, é preciso também considerar que, os interesses econômicos influenciaram a elaboração das normas ambientais internacionais. Primeiramente procurando garantir a continuidade de atividades econômicas e abastecimento de comunidades onde os recursos naturais são mais escassos. Em outros casos, os recursos naturais mais escassos tem seu preço elevado, por isso são mais disputados no comércio internacional, a exemplo do marfim, da madeira da Amazônia, entre outros.

Sendo assim, as normas internacionais nunca foram pacificamente implementadas em sua plenitude. Daí a carência de sua eficácia.

\section{Referências bibliográficas}

BACHELET, Michel. A ingerência ecológica: direito ambiental em questão. Lisboa: Instituto Piaget, 1997.

CARRERA, Francisco; SÉGUIN, Elida. Planeta Terra: uma abordagem de Direito Ambiental. 2 ed. Rio de Janeiro: Lumen Juris, 2001.

CEZARIO, Leandro Fazollo. O Caso da Fundição Trail (Trail Smelter Case) - Estados Unidos X Canadá: Características Transfronteiriças dos Danos ao Meio Ambiente e a Responsabilidade Internacional do Estado por Danos Ambientais. Portal Jurídico Investidura, Florianópolis/SC, 22 Jun. 2010. Disponível em: www.investidura.com.br/bibliotecajuridica/artigos/direito-ambiental/164152. Acesso em: 30 Nov. 2011.

Declaração do Rio sobre Meio Ambiente e Desenvolvimento, 1992. Disponível em http://www.mma.gov.br/sitio/index.php? $\mathrm{ido}=$ conteudo.monta\&idEstrutura=18\&idConteudo=576. Acesso em 29/03/2011.

DERANI, Cristiane. Direito Ambiental Econômico. 3 ed. São Paulo: Saraiva, 2008.

; RIOS, Aurélio Virgio Veiga. Princípios do Direito Internacional Ambiental. In.: O direito e o desenvolvimento sustentável: curso de direito ambiental. Org.: RIOS, Aurélio Virgílio Veiga. São Paulo: Peirópolis, 2005. p. 87-122. 
160

GUERRA, Sidney. Globalização na Sociedade de Risco e o Princípio da Não-indiferença em matéria ambiental. In.: Globalização: desafios e implicações para o direito internacional contemporâneo. Org. GUERRA, Sidney. Ijuí, RS: UNIJUÍ, 2006. p. 435-458.

OLIVEIRA, Rafael Santos de. Direito Ambiental Internacional: o papel da soft low em sua efetivação. Ijuí: Uniijuí, 2007. p. 104.

Programa das Nações Unidas pra o Meio Ambiente. Disponível em: $<$ http://www.onubrasil.org.br/agencias_pnuma.php> Acesso em 26/03/2010.

SOARES, Guido Fernando da Silva. Direito Internacional do Meio Ambiente: emergência, obrigações e responsabilidades. 2 ed. São Paulo: Atlas, 2003.

VARELLA, Marcelo Dias. Direito Internacional Econômico Ambiental. Belo Horizonte: Del Rey, 2003.

VIANA, Rui Geraldo Camargo. A política ambiental em nível internacional e sua influência no direito pátrio. In: O Direito Internacional do terceiro milênio: estudos em homenagem ao professor Vicente Marotta Rangel. Coord.: BAPTISTA, Luiz Olavo; FONSECA, José Roberto Franco. São Paulo: LTr, 1998. p. 920-925.

WOLD, Chris. Emergência de um conjunto de princípios destinados à proteção internacional do meio ambiente. In.: Princípios de direito ambiental: na dimensão internacional e comparada. Belo Horizonte: Del Rey, 2003. p. 5-31

Artigo recebido em 30 de novembro de 2011 e aceito em 02 de fevereiro de 2012. 